

\title{
Editorial
}

\section{Workplace violence - Is anybody really safe?}

\author{
Malcolm Boyle PhD, Editor and Academic Lead in Paramedic Education ${ }^{1}$; Jaime Wallis BEH is a lecturer in \\ paramedicine $^{1}$
}

\author{
Affiliations: \\ ${ }^{1}$ Griffith University, School of Medicine, Queensland
}

The Australian Human Rights Commission recently released the research commissioned by 39 Australian universities into sexual harassment and sexual assault on students (1). In summary, the research found that: over 30,000 students participated in the study from 39 universities; $21 \%$ of students were sexually harassed and $1.6 \%$ of students sexually assaulted. Of concern was the $94 \%$ of students who were sexually harassed and the $87 \%$ of students who were sexually assaulted that did not formally report the incident. From this information, one must question whether this follows a similar societal trend or some other factors are in play (1).

The organisation that represents Australian universities - Universities Australia, which commissioned the study - has now launched a campaign to highlight the issue of sexual harassment and sexual assault and to ensure there are appropriate support measures for victims in place at each university (2).

Violence against paramedics in the workplace by patients, friends, relatives and bystanders (3-5), has been communicated loudly within the media. However, what about the issue of workplace violence from within the ambulance service?

An Australian study into acts of workplace violence against paramedics found that $16 \%$ experienced sexual harassment and $4.3 \%$ experienced sexual assault, with the majority of those affected being female (6). The perpetrators of this violence against the paramedics was work colleagues and other professionals who accounted for $37.2 \%$ of the perpetrators for sexual harassment and $46.2 \%$ for sexual assault (7).

Ambulance services are providing staff with educational support surrounding occupational violence in addition to the initiation of media campaigns about the issue of workplace violence against paramedics while on the job (8). However, there appears to be little done about acts of workplace violence by fellow ambulance staff, such as sexual harassment and sexual assault.

Research has shown that acts of workplace violence by colleagues is far more divisive to a person's wellbeing than that from external sources (9). A study by Hershcovis and Barling demonstrated that violence from a colleague had a greater effect on decreasing job satisfaction and emotional commitment to the job than violence from an external perpetrator, such as a customer (9).

An Australian study that explored acts of workplace violence against paramedic and midwifery students while they were on clinical placement, found that $1.2 \%$ of paramedic and $5.8 \%$ of midwifery students were sexually harassed (10). All students sexually harassed were female. The majority of the perpetrators of sexual harassment were the mentors of the students (11).

Like the university students, the paramedic and midwifery students did not report the violent incident to staff at the institution they were undertaking their placement, or their university (11). Of concern was the paramedic student who experienced multiple acts of sexual harassment, but did not report it (10). There was a level of fear associated with the sexual harassment and the ramifications, which may explain the lack of reporting (11). What was found in this study was that the students were more likely to discuss the incident with a family member and/or friend, or fellow student (11). 
A separate study investigated the reasons why paramedic students did not report acts of workplace violence against them. Predominately students found it difficult to trust people within the ambulance service or university with this sensitive information. Other explanations included not wanting to interfere with their employment opportunities, reporting the violence may not change anything, and being unsure of the appropriate reporting procedure (12).

Vulnerable students - who may be in their late teens - need to be educated in what constitutes acts of workplace violence and clear processes for reporting an incident need to be available, and to a certain degree, a level of anonymity for the student, if desired.

As for the future, the fearful culture that surrounds reporting an incident of workplace violence requires organisations to be decisive about the way they handle the issue.

Workplace violence is an ongoing issue; it is questionable whether it can be eliminated from the patient paramedic interface. However, it can and should be eliminated from all other areas of the workplace. Education, strong willed organisations and resetting the social norms will go a long way to removing colleague-to-colleague acts of workplace violence.

Dr Mal Boyle

Editor

Australasian Journal of Paramedicine

Jaime Wallis

Griffith University, Queensland

\section{References}

1. Australian Human Rights Commission. Change the Course: National Report on Sexual Assault and Sexual Harassment at Australian Universities (2017). Sydney: Australian Human Rights Commission; 2017.

2. Universities Australia. Student safety - Respect. Now. Always (2017). Available at: www.universitiesaustralia.edu.au/uniparticipation-quality/students/Student-safety/Respect--Now--Always- [Accessed 2 August 2017].

3. Paramedics threatened with knives, held hostage; figures show attacks increasing. ABC; 2015. Available at: www.abc.net. au/news/2015-02-18/violence-against-victorian-paramedics-increased-by-69-per-cent/6132934

4. Diefenbach R. Queensland paramedic allegedly assaulted in moving ambulance. The Huffington Post (Aust); 13 December 2015.

5. Zielinski C. Vic paramedic assaulted on duty. Melbourne: 7 News; 25 December 2015.

6. Boyle MJ, Koritsas S, Coles JY, Stanley JR. A pilot study of workplace violence towards paramedics. Emerg Med J 2007;24:760-3.

7. Boyle M, Koritsas S, Coles J, editors. Perpetrators of violence against paramedics in the workplace and the paramedic's response. The Second International Conference on Violence in the Health Sector; 2010; Amsterdam, The Netherlands: Kavanah.

8. Crouch B. SA Government launches campaign to stop violence against health workers. The Advertiser; 27 May 2015.

9. Hershcovis MS, Barling J. Towards a multiffoci approach to workplace aggression: a metalanalytic review of outcomes from different perpetrators. J Organ Behav 2010;31:24-44.

10. Boyle M, McKenna L. Paramedic and midwifery student exposure to workplace violence during clinical placements in Australia - a pilot study. Int J Med Educ 2016;7:393-9.

11. Boyle M, McKenna L, editors. Are paramedic and midwifery students exposed to workplace violence during clinical placements? The Third International Conference on Violence in the Health Sector; 2012; Vancouver, Canada. Amsterdam, The Netherlands: Kavanah; 2012.

12. Boyle M, Wallis J, editors. Why don't student paramedics report acts of workplace violence against them? The Fifth International Conference on Violence in the Health Sector; 2016; Dublin, Ireland: Kavanah. 